\title{
Bir Üniversite Hastanesinin 3 Yıllık Obezite ve Diyabet Prevalansı: Erişkin ve Çocukluk Çağı Verilerinin Retrospektif Analizi
}

\author{
Nurhayat ÖZKAN SEVENCAN৫ $₫$, Ayşegül ERTINMAZ ÖZKAN® \\ Karabük Üniversitesi Tıp Fakültesi, İç Hastalıkları Anabilim Dalı, Karabük \\ Bu makaleye yapılacak atıf: Özkan Sevencan N, Ertınmaz Özkan A. Bir Üniversite Hastanesinin 3 Yıllık Obezite ve Diyabet Prevalansı: Erişkin ve Çocukluk Çağı Verilerinin \\ Retrospektif Analizi. Türk Diyab Obez 2019;1: 31-36.
}

\begin{abstract}
ÖZET
Amaç: Obezite tüm dünyada olduğu gibi ülkemizde de hızla artan önemli bir halk sağlığı sorunudur. Dünya Sağlı Örgütü (DSÖ) verilerine göre 2016 yılı için Türkiye \%29,5 prevalans ile Avrupa'da obezitenin en sık görüldüğü ülke olmuştur. Biz bu çalışmada hastanemize başvuran hastaların kayıtlarına dayanarak bölgemizde erişkin ve çocukluk yaş gruplarındaki obezite ve diyabet prevalansını ortaya koymayı amaçladık.

Gereç ve Yöntemler: 2016-2018 yılları arasında Karabük Üniversitesi Eğitim ve Araştırma Hastanesi diyet polikliniğine başvuran hastaların 3 yıllık kayıtları geriye dönük olarak incelendi. Yaş ve cinsiyete göre vücut kütle indeksi (VKİ) düzeyleri, diyet polikliniğine geliş nedenleri, obezite ve diyabet oranları değerlendirildi.

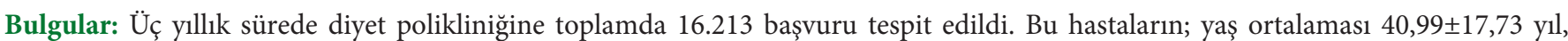
$\% 64,1$ 'i $(n=10.383)$ kadındı. 18 yaş altı hastaların \%60,8’i $(n=660), 18$ yaş ve üzeri hastaların \%32,6'sı (n=4.509) kilo verdirici diyet,

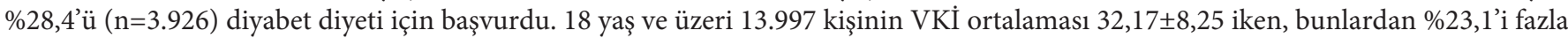
kilolu (VKİ 25-29,99), \%45,4’ü obez (VKİ 30-39), \%14,5’i ise morbid obez (VKİ $\geq 40$ ) idi. 2.428 kadın, 1.663 erkek hasta diyabetik idi. Kadın hastaların 1.705'i fazla kilolu, 4.374'ü obez, 1.759'u morbid obez iken erkek hastaların 1.534'ü fazla kilolu, 1.835'i obez, 270'i morbid obez idi. 3.887 diyabetik hastanın 897'si fazla kilolu, 2.189'u obez, 598'i morbid obez idi. 18 yaş ve üzeri, VKİ $\geq 25$ olan hastaların büyük bir kısmının aynı zamanda diyabetik de olduğu, obezite ve diyabetin yakın ilişkide olduğu saptandı.

Sonuç: Bölgemizde hem çocuk hem de erişkin obezitesi ciddi boyutlardadır. Dahası, kadın cinsiyet obezite ve diyabet açısından erkeklere nazaran daha büyük risk altındadır. Toplumda farkındalık artmasına rağmen maalesef obezite oranı artışının önüne geçilememektedir. Anahtar Sözcükler: Obezite, Diyabet, Diyet polikliniği verileri
\end{abstract}

\section{3-Year Obesity and Diabetes Prevalence of a University Hospital: Retrospective Analysis of Adult and Childhood Data}

\begin{abstract}
Aim: Obesity is an important public health issue that is rapidly increasing in our country and around the world. According to the World Health Organization (WHO), Turkey has the most cases of obesity in Europe with $29.5 \%$ prevalence in 2016. In this study, we aimed to perform obesity and diabetes prevalence of adult and childhood groups in our region based on patient records admitted to our hospital. Material and Methods: 3-year records of patients admitted to the Karabuk University Education and Research Hospital, diet outpatient clinic between the years of 2016 to 2018 retrospectively were examined the patient's body mass index (BMI) levels according to age and gender.

Results: A total of 16,213 applications were determined in the Diet outpatient clinic for 3 years. These determined patients; the mean age was $40.99 \pm 17.73$ years, $64.1 \%(n=10,383)$ was female. The $60.8 \%$ of patients under 18 years of age $(n=660), 32.6 \%$ of patients are over
\end{abstract}

Bu çalışma, 22-25 Kasım 2018 tarihinde Ankara'da düzenlenen Ulusal Obezite Kongresi’nde Sözlü Sunum olarak sunulmuştur.

ORCID: Nurhayat Özkan Sevencan / 0000-0001-9013-3517, Ayşegül Ertınmaz Özkan / 0000-0002-3273-1305 
18 years $(n=4,509)$ were admitted a diet to lose weight, $28.4 \%(n=3,926)$ for the specific diabetes diet. The mean of 13,997 people over 18 years of age were $32.17 \pm 8.25,23.1 \%$ were overweight (BMI 25-29.99), 45.4\% obese (BMI 30-39), 14.5\% were morbid obese (BMI $\geq$ 40). The 2,428 females and 1,663 male patients were diabetic, and 1,705 of females were overweight, 4,374 obese, and 1,759 were morbid obese. While 1,534 of male patients were overweight, 1,835 obese and 270 were morbid obese, and of 3,887 diabetic patients had 897 overweight, 2,189 obese and 598 were morbid obese. Most of the patients who were over the age of 18 and BMI $\geq 25$ were also diabetic; results indicate obesity and diabetes are in close relationship.

Conclusion: Both children and adult obesity in our region are of serious proportions. Moreover, females are at greater risk than men in terms of obesity and diabetes. Despite the increase in public awareness, unfortunately the increase in obesity rate cannot be prevented.

Key Words: Obesity, Diabetes, Diet outpatient data

\section{GíRiș}

Obezite dünya genelinde geniş kitleleri etkileyen önemli bir halk sağlığı sorunudur. Hem gelişmiş ülkelerde hem de gelişmekte olan ülkelerde hızla artış göstermektedir. Çocukluk, adolesan ve erişkin yaş gruplarındaki önlenemeyen artış oranları prevansiyonun önemini bir kat daha artırmaktadır $(1,2)$.

Başta Dünya Sağlık Örgütü (DSÖ) olmakla birlikte, toplumsal sağlık verileri ile ilgili birçok kurum obezite sıklığının yıllar içerisindeki artışını yakından izlemekte ve toplum sağlığını korumaya yönelik önlemler almaya çalışmaktadır (3). DSÖ verilerine göre dünya çapında obezite sıklı̆̆ 1 (vücut kütle indeksi [VKİ] $\geq 30 \mathrm{~kg} / \mathrm{m}^{2}$ ) 1975 'ten bu yana neredeyse üç kat artış göstermiştir. Dünyada 340 milyon çocuk ve adolesan, 1,9 milyar erişkinin fazla kilolu ve obez olduğu tahmin edilmektedir. Her yıl yaklaşık 2,8 milyon kişi kilo fazlalığı veya obezite nedeni ile yaşamını yitirmektedir (4-6).

Türkiye'de obezite sıklığını araştıran ilk epidemiyolojik çalışma TEKHARF (1991 yılı) çalışmasıdır (7). Ondan daha kapsamlı olan TURDEP-I (1997-98 yılları) çalışmasına göre erişkinlerdeki obezite prevalansının \%22,3 olduğu saptanmıştır (8). TURDEP-II (2010 y1lı) verilerine göre ise Türkiye'de obezite sıklığı \%32'ye ulaşmıştır. Genel olarak erişkin yaşlardaki Türk toplumunun 2/3'ü kilolu veya obezdir (9). DSÖ ise 2016 yllında, Türkiye'de 16.092.644 obez birey bulunduğunu ve \%29,5 prevalans ile Türkiye'nin, Avrupa'da obezitenin en sık görüldüğü ülke olduğunu bildirmektedir (10).

Obez bir toplum olduğumuz bu şekilde tescillenmiş iken biz bu çalışmada; hastanemize başvuran hastaların verilerine dayanarak bölgemizdeki obezite ve diyabet oranlarını ve obezitenin derecesini araştırmayı amaçladık. Karabük ilimiz, bünyesinde barındırdığı demir çelik işletmeleri nedeniyle Türkiye'nin her bölgesinden yoğun göç alan kozmopolit yapıda bir şehirdir. Karabük Eğitim Araştırma Hastanesi ise hem ilimize hem de Batı Karadeniz Bölgesi'ne hitap eden yüksek hasta kapasitesine sahip önemli bir hastanedir. Dolayssiyla hastane verilerimizin metaanalizi ile bölgemiz ve hatta ülkemiz erişkinlerindeki obezitenin düzeyine ilişkin güvenilir bir kaynak oluşturabileceği düşüncesindeyiz.

\section{GEREÇ ve YÖNTEMLER}

Bu retrospektif çalışma için Karabük Üniversitesi girişimsel olmayan klinik uygulamalar etik kurulundan onay alındı (Karar No:2018/9-3). 2016-2018 yılları arasinda Karabük Üniversitesi Eğitim ve Araştırma Hastanesi diyet polikliniğine başvuran hastaların 3 yıllık kayıtları incelendi. Hastalar geliş nedenlerine göre başlica 8 gruba ayrildı. Kontrol hastaları ise ayrı bir grup olarak değerlendirildi ve mükerrer kayıt olasılığını önlemek için bu grubun verileri analizlerden çıkarıldı. Hastalar 18 yaş altı, 18 yaş ve üzeri olarak da iki gruba ayrıldı. Ortalama değerlerini etkilememesi açısından 18 yaş altı hastaların boy, kilo, VKİ verileri değerlendirmelere dahil edilmedi.

\section{İstatistiksel Analiz}

Tanımlayıcı istatistik için sürekli değişkenler ortalama \pm standart sapma, kategorik veriler ise sayı ve yüzde şeklinde ifade edildi. Kategorik verilerin karşılaştırılmasında Kikare Testi kullanıldı. Analizler, IBM SPSS Paket Programı versiyon 24.0 (IBM Corporation, Armonk, NY, ABD) ile yapıldı. İstatistiksel anlamlılık düzeyi $\mathrm{p}<0,05$ olarak ele alınd.

\section{BULGULAR}

Diyet polikliniğine başvuran toplam 16.213 hastanın yaş

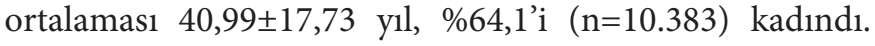
18 yaş üstü hastaların VKİ ortalaması $32,17 \pm 8,25$ idi. Hastaların yıllara göre yaş ve cinsiyet dağılımları Şekil 1 ve Şekil 2'de sunulmuştur.

Diyet polikliniğine başvurma nedenlerine bakıldığında; 18 yaş altı hastaların \%60,8'i ( $\mathrm{n}=660)$ kilo verdirici diyet için, $\% 8,6$ 'sı ( $\mathrm{n}=94)$ kilo aldırıcı diyet için başvurmuş iken, 18 yaş ve üzeri hastaların \%32,6'sı $(\mathrm{n}=4.509)$ kilo verdirici diyet için, \%28,4'ü $(n=3.926)$ diyabet diyeti için başvurmuştu (Tablo 1). 
Tablo 1. Yaşa göre diyet polikliniğine başvurma nedenleri.

\begin{tabular}{lcccccc}
\hline \multirow{2}{*}{ Diyet polikliniğine başvurma nedenleri } & \multicolumn{2}{c}{$<\mathbf{1 8}$ yaş } & \multicolumn{2}{c}{$\geq \mathbf{1 8}$ yaş } & \multicolumn{2}{c}{ Toplam } \\
\cline { 2 - 7 } & $\mathbf{n}$ & $\mathbf{0}$ & $\mathbf{n}$ & $\mathbf{0}$ & $\mathbf{n}$ & $\mathbf{\%}$ \\
\hline Kilo vermek için diyet & $\mathbf{6 6 0}$ & $\mathbf{6 0 , 8}$ & $\mathbf{4 5 0 9}$ & $\mathbf{3 2 , 6}$ & $\mathbf{5 1 6 9}$ & $\mathbf{3 4 , 6}$ \\
\hline Diyabet diyeti & 12 & 1,1 & $\mathbf{3 9 2 6}$ & $\mathbf{2 8 , 4}$ & $\mathbf{3 9 3 8}$ & $\mathbf{2 6 , 4}$ \\
\hline Kontrol & $\mathbf{1 4 0}$ & $\mathbf{1 2 , 9}$ & $\mathbf{1 1 9 7}$ & $\mathbf{8 , 7}$ & $\mathbf{1 3 3 7}$ & $\mathbf{9 , 0}$ \\
\hline Reflü-gastrit-kabızlık diyeti & 65 & 6,0 & 740 & 5,4 & 805 & 5,4 \\
\hline Hiperlipidemi, yağlı karaciğer diyeti & 7 & 0,6 & 671 & 4,9 & 678 & 4,5 \\
\hline Kilo almak için diyet & $\mathbf{9 4}$ & $\mathbf{8 , 7}$ & 388 & 2,8 & 482 & 3,3 \\
\hline Gestasyonel diyabet diyeti & 0 & 0,0 & 279 & 2,0 & 279 & 1,9 \\
\hline Glutensiz diyet & 3 & 0,3 & 16 & 0,1 & 19 & 0,1 \\
\hline Diğer & 105 & 9,7 & 2104 & 15,2 & 2209 & 14,8 \\
\hline Toplam & $\mathbf{1 0 8 6}$ & $\mathbf{1 0 0 , 0}$ & $\mathbf{1 3 8 3 0}$ & $\mathbf{1 0 0 , 0}$ & $\mathbf{1 4 9 1 6}$ & $\mathbf{1 0 0 , 0}$ \\
\hline
\end{tabular}

18 yaş ve üzeri toplam 13.997 kişinin VKİ ortalaması $32,17 \pm 8,25$ idi. Kadınlar ortalama $156 \mathrm{~cm}$ boy, $82 \mathrm{~kg}$ ağırlığa sahip iken, erkekler ortalama $170 \mathrm{~cm}$ boy ve $84 \mathrm{~kg}$ ağırlığa sahipti. 18 yaş üstü kadınların ortalama VKİ değeri 33,90, erkeklerin ortalama VKİ değeri 29,14 olarak saptandı. Kadın ve erkek cinsiyete göre ortalama boy, kilo ve VKİ değerleri Tablo 2'de sunulmuştur.

Diyet polikliniğine başvuran kadın hastaların \%37,6'sı $(\mathrm{n}=3.898)$ kilo verdirici diyet için, \%23,4' $\ddot{\mathrm{u}}(\mathrm{n}=2.428)$ diyabet diyeti için başvurmuş iken, erkek hastaların \%30,4'ünün $(\mathrm{n}=1.663)$ kilo verdirici diyet için, \%31,3'ünün $(\mathrm{n}=1.712)$ diyabet diyeti için başvurduğu saptand $1(\mathrm{p}<0,001)$ (Tablo 3 ).

18 yaş ve üzeri toplam başvuruların \%2,2'si zayıf ( $\mathrm{VKI}<18,5)$, \%15,8'i normal kilolu (VKİ 18,5-24,9), \%23,1'i fazla kilolu (VKİ 25-29,99), \%45,4'ü obez (VKİ 30-39), \%14,5’i ise
Tablo 2. 18 yaş ve üzeri hastaların ortalama boy, kilo ve VKİ değerleri.

\begin{tabular}{lcc}
\hline & Kadın & Erkek \\
\hline Boy $(\mathrm{cm})$ & $156,40 \pm 15,28$ & $170,64 \pm 7,78$ \\
\hline Kilo $(\mathrm{kg})$ & $82,60 \pm 20,48$ & $84,69 \pm 18,98$ \\
\hline VKİ $\left(\mathrm{kg} / \mathrm{m}^{2}\right)$ & $33,90 \pm 33,39$ & $29,14 \pm 6,55$ \\
\hline
\end{tabular}

morbid obez (VKI $\geq 40)$ idi. Kadın ve erkekler arasında VKİ düzeyleri bakımından istatistiksel anlamlı fark vardı $(\mathrm{p}<0,001)$ (Tablo 3).

18 yaş ve üzeri hastaların başvuru nedenleri ve VKİ oranları karşılaştırıldığında; VKİ $\geq 25$ olan hastaların büyük bir kısmının aynı zamanda diyabetik de olduğu, obezite ve diyabetin yakın ilişkide olduğu saptandı (Tablo 4).

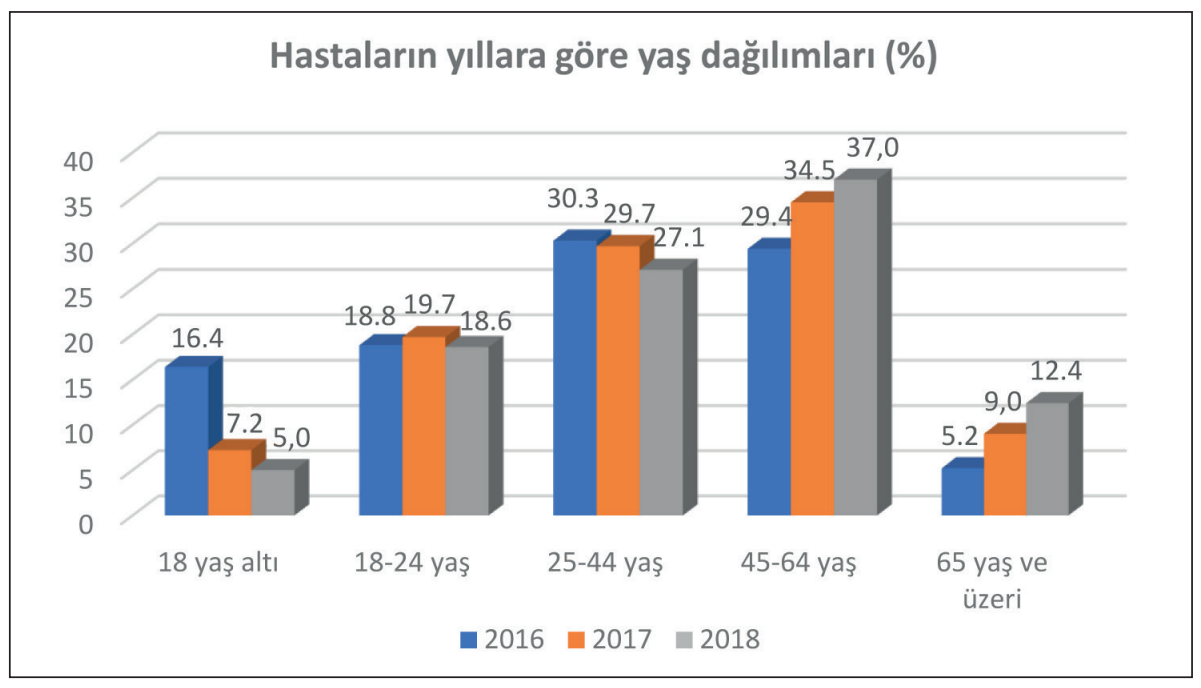

Şekil 1: Diyet polikliniğine başvuran hastaların yıllara göre yaş dağılımı. 


\section{TARTIŞMA}

Hastanemiz diyet polikliniğinin geriye dönük 3 yllık kayıtları incelendiğinde 16.213 hasta başvurusuna ulaşıldı (\%64,1'i kadın). 18 yaş ve üzeri hastaların \%23,1'i fazla kilolu, \%45,4'ü obez, \%14,5'i ise morbid obezdi. 2.428 kadın, 1.663 erkek hasta diyabetik idi. Kadın hastaların 1.705 'i fazla kilolu, 4.374'ü obez, 1.759'u morbid obez iken erkek hastaların 1.534 'ü fazla kilolu, 1.835 'i obez, 270 'i morbid obez idi. 3.887 diyabetik hastanın 897'si fazla kilolu, 2.189'u obez, 598'i morbid obez idi. Kadınlarda hem diyabet hem de obezite erkek cinsiyete oranla belirgin derecede yüksek bulundu. 120.000 nüfuslu küçük bir il olan Karabük için

Tablo 3. Cinsiyete göre VKİ ve diyet polikliniğine başvurma nedenlerinin karşılaştırılması.

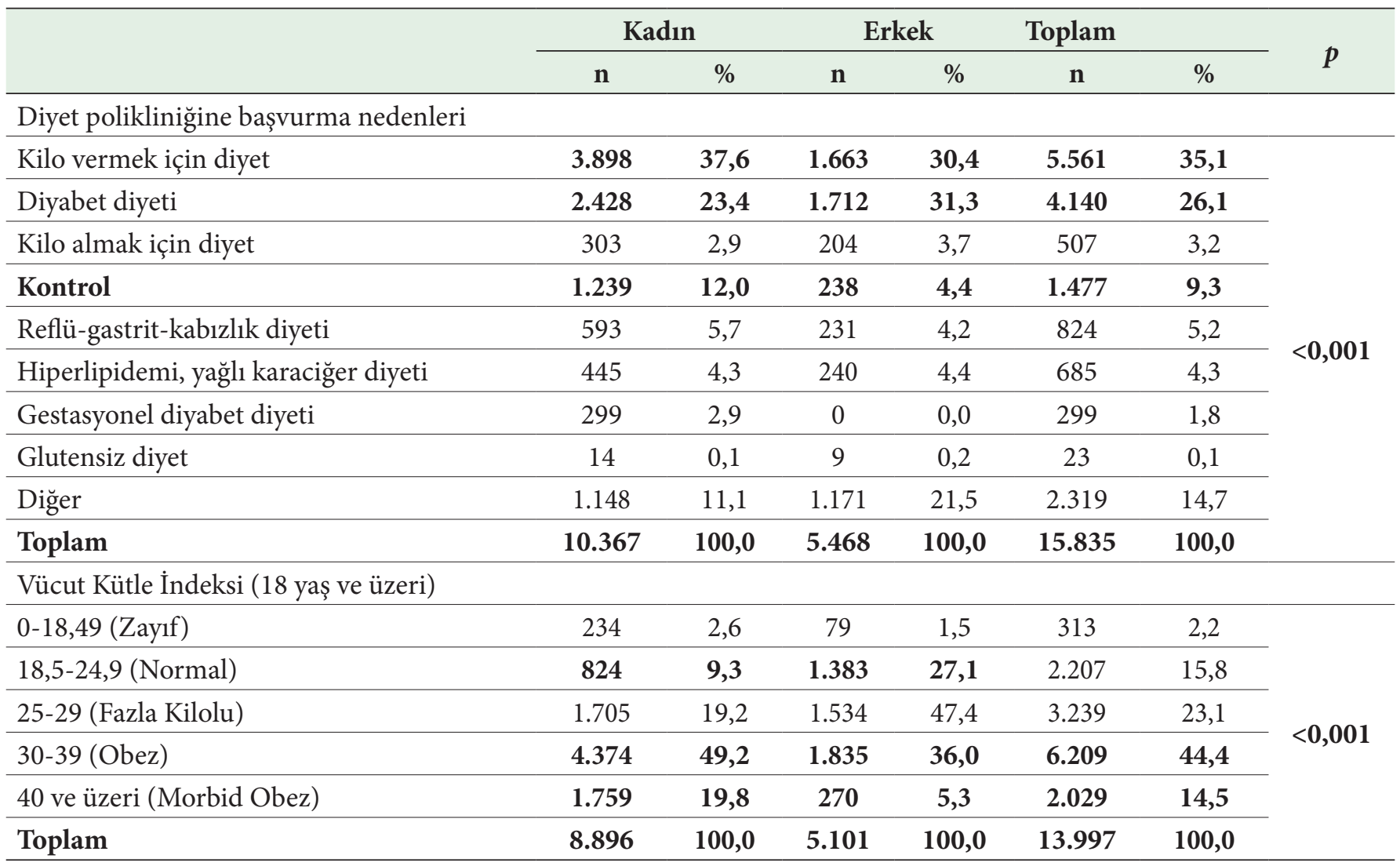

* Ki kare Testi.

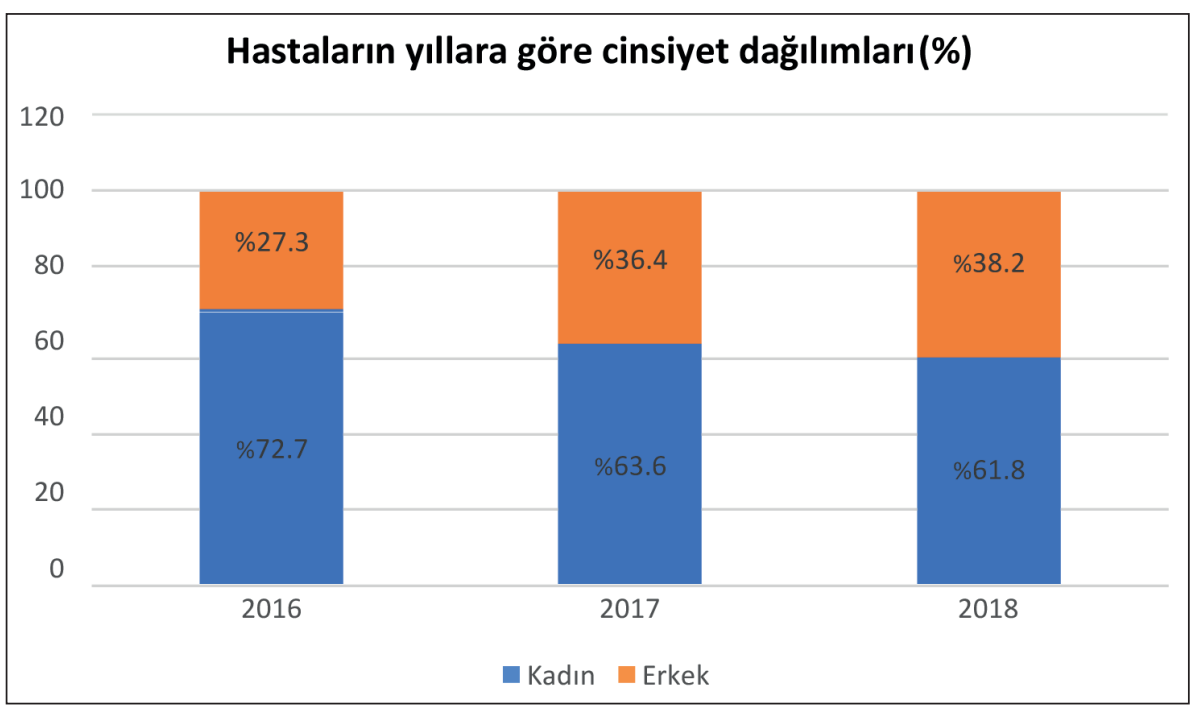

Şekil 2: Diyet polikliniğine başvuran hastaların yıllara göre cinsiyet dağılımı. 
bu derece yüksek obezite ve diyabet oranları bölgemiz açısından durumun ciddiyetini gözler önüne sermektedir.

Özellikle ekonomik açıdan zengin ülkeleri etkilemekle birlikte obezite ve Tip 2 diabetes mellitus (T2DM), dünyanın her yerinde durmaksızın bir artış göstermektedir $(11,12)$. Kentleşmenin artması, yaşlanan nüfus, şişmanlık ve azalan fiziksel aktivite seviyeleri, T2DM'nin dünya çapındaki artışına katkıda bulunmaktadır. Bilimsel araştırmalara göre, Suudi Arabistan dünyadaki en yüksek T2DM prevalansına sahip ülkedir. Amerika Birleşik Devletleri, İsviçre ve Avusturya'daki yetișkinlerin \%10'undan fazlasının da T2DM olduğu tespit edilmiştir (12). Bu metabolik bozuklukta obezite ve vücut yağının rolü vurgulanmaktadır. T2DM salgınının ana nedeni artan obezite prevalansıdır. Bugüne kadar, sadece DSÖ değil birçok bilimsel dernek ve toplumsal kuruluş bulaşıcı olmayan hastalıkların önlenmesinde diyetin rolü üzerinde giderek daha fazla durmaktadır (13).

Metabolik hastalıklara yönelik ülkemizdeki prevalans çalışmalarından ilki 1991 yılında yayınlanan TEKHARF çalışmasıdır. Türkiye'nin yedi coğrafi bölgesinden seçilen
3.689 kişinin incelenmesi neticesinde obezite; erkeklerde $\% 9$ oranında iken, kadınlarda \%30'a kadar yükselebilen oranlarda bulunmuştur. Diyabet prevalansı ise kadınlarda $\% 4$, erkeklerde \%2,5 olarak tespit edilmiştir (7). Yine TEKHARF çalışması 1997/98 verilerine göre erişkin yaş grubundaki Türk erkeklerinde ortalama VKİ:26,5 iken kadınlarda 28,7 olarak saptanmıştır (14).

2002 yılında yayınlanan TURDEP-I çalışmasında 24.788 gönüllü (\%55,3’ü kadın) çalışmaya dahil edilmiştir. Toplumda obezite prevalans1 \%22, diyabet $\% 7,2$ ve bozulmuş glukoz toleransı (IGT) \%6,7 olarak saptanmıștır. Bel çevresine göre hesaplandığında ise santral obezite prevalansı \%34'lere kadar yükselmekte idi. Tüm bu göstergeler kadınlarda erkeklere oranla istatistiksel olarak anlamlı düzeyde daha yüksek bulunmuştur. Türkiye'nin doğusunda yaşayanlar en düşük diyabet (\%6), IGT (\%6) ve obezite (\%17) prevalansına sahip iken, diyabet için en yüksek oranlar (\%9) güney bölgesinde, obezite ise (\%27) Orta Anadolu bölgesinde idi (8).

Tablo 4. Diyet polikliniğine başvurma nedenlerine göre VKİ karşılaştırması.

\begin{tabular}{|c|c|c|c|c|c|c|c|}
\hline \multirow{2}{*}{$\begin{array}{l}\text { Diyet polikliniğine } \\
\text { başvurma nedenleri }\end{array}$} & & \multicolumn{6}{|c|}{ Vücut Kütle İndeksi } \\
\hline & & $\begin{array}{l}0-18,49 \\
\text { (Zayıf) }\end{array}$ & $\begin{array}{l}18,5-24,9 \\
\text { (Normal) }\end{array}$ & $\begin{array}{c}25-29 \\
\text { (Fazla kilolu) }\end{array}$ & $\begin{array}{c}30-39 \\
(\text { Obez })\end{array}$ & $\begin{array}{c}40 \text { ve üzeri } \\
\text { (Morbid obez) }\end{array}$ & Toplam \\
\hline \multirow{2}{*}{ Kilo vermek için diyet } & $\mathrm{n}$ & 5 & 212 & 1.131 & 2.147 & 984 & 4.479 \\
\hline & $\%$ & 1,6 & 11,0 & 35,5 & 34,6 & 48,6 & 32,8 \\
\hline \multirow{2}{*}{ Diyabet diyeti } & $\mathrm{n}$ & 6 & 197 & 897 & 2.189 & 598 & 3.887 \\
\hline & $\%$ & 1,9 & 10,2 & 28,2 & 35,3 & 29,5 & 28,5 \\
\hline \multirow{2}{*}{ Kilo almak için diyet } & $\mathrm{n}$ & 209 & 169 & 0 & 0 & 0 & 378 \\
\hline & $\%$ & 66,8 & 8,8 & 0,0 & 0,0 & 0,0 & 2,7 \\
\hline \multirow{2}{*}{ Kontrol } & $\mathrm{n}$ & 20 & 37 & 235 & 636 & 255 & 1.183 \\
\hline & $\%$ & 6,4 & 1,9 & 7,4 & 10,2 & 12,6 & 8,7 \\
\hline \multirow{2}{*}{ Glutensiz diyet } & $\mathrm{n}$ & 0 & 11 & 4 & 1 & 0 & 16 \\
\hline & $\%$ & 0,0 & 0,6 & 0,1 & 0,0 & 0,0 & 0,1 \\
\hline \multirow{2}{*}{$\begin{array}{l}\text { Gestasyonel diyabet } \\
\text { diyeti }\end{array}$} & $\mathrm{n}$ & 2 & 26 & 73 & 152 & 23 & 276 \\
\hline & $\%$ & 0,6 & 1,3 & 2,3 & 2,4 & 1,1 & 2,0 \\
\hline \multirow{2}{*}{$\begin{array}{l}\text { Reflü-gastrit-kabızlık } \\
\text { diyeti }\end{array}$} & $\mathrm{n}$ & 11 & 209 & 211 & 259 & 24 & 714 \\
\hline & $\%$ & 3,5 & 10,8 & 6,6 & 4,2 & 1,2 & 5,2 \\
\hline \multirow{2}{*}{$\begin{array}{l}\text { Hiperlipidemi, yağlı } \\
\text { karaciğer }\end{array}$} & $\mathrm{n}$ & 3 & 45 & 182 & 345 & 84 & 659 \\
\hline & $\%$ & 1,0 & 2,3 & 5,7 & 5,6 & 4,1 & 4,8 \\
\hline \multirow{2}{*}{ Diğer } & $\mathrm{n}$ & 57 & 1.024 & 450 & 479 & 58 & 2.068 \\
\hline & $\%$ & 18,2 & 53,1 & 14,1 & 7,7 & 2,8 & 15,2 \\
\hline \multirow{2}{*}{ Toplam } & $\mathrm{n}$ & 313 & 1.930 & 3.183 & 6.208 & 2.026 & 13.660 \\
\hline & $\%$ & 100,0 & 100,0 & 100,0 & 100,0 & 100,0 & 100,0 \\
\hline
\end{tabular}


2013 yılında yayınlanan TURDEP-II çalışmasında ise 26.499 gönüllü (\%63'ü kadın) çalışmaya dahil edildi. Erkeklerde ortalama VKİ:27,4 iken kadınlarda 29,2 olarak saptandi. Diyabet prevalansı $\% 16,5$, prediyabet $\% 30,8$, fazla kilolu olma \%37, obezite $\% 36$ ve santral obezite $\% 54$ idi (9). TURDEP-I ve II karşılaştıııldığında diyabet, IGT ve obezite prevalansında sırasıyla \%90, 106 ve 40 oranında artış olduğu görülmüştür. Türkiye nüfusu giderek yaşlanmakla birlikte erkelerde ortalama yaşam beklentisi 67 ylldan 72'ye, kadınlarda 73 yıldan 77’ye yükselmiştir (15).

Tüm bu veriler değerlendirildiğinde giderek şişmanlayan ve yaşlanan, diyabetik bir toplum haline geldiğimiz aşikardır. Kadınlar için durum erkeklere nazaran daha vahim olarak görünmektedir. Obez kadınların beslenme tarzı obez çocukların da giderek artışına neden olmaktadır. Nitekim bizim çalışmamızda 660 çocuk hasta kilo vermek amacıyla diyet polikliniğimize başvurmuştur. Kadın hastaların da 3.898'i kilo vermek için, 2.428'i diyabetik diyet için başvurduğu hesaba katılırsa kadın nüfusunun büyük bir kısmının obez ve diyabetik olduğu anlaşılmaktadır. Bu rakamlar sadece hastane kayitlarımıza dayanarak elde edilmiş iken toplumda henüz obezite farkındalığ olmayan, obeziteyi bir hastalık olarak görmeyen ciddi bir popülasyonun olması da buz dağının görünmeyen yüzünü oluşturmaktadır.

Modern dünyada çı̆̆ gibi büyüyen obezite hem çocukluk hem de erişkin yaş grupları için ciddi bir sağlık tehditi oluşturmaktadır. Toplumda obezite ve diyabetten muzdarip ciddi bir popülasyon olmasına rağmen kilo veremeyen, şeker regülasyonu sağlanamayan müzmin bir hasta profili ile karşı karşıya kaldığımız aşikardır. Obezite sadece endokrinoloji ve iç hastalıkları uzmanlarını değil, birçok alan hekimini ilgilendiren önemli bir sorundur. Toplumda farkındalık artmasına rağmen maalesef obezite oranı artışının önüne geçilememektedir.

\section{KAYNAKLAR}

1. Abarca-Gómez L, Abdeen ZA, et al. Worldwide trends in body-mass index, underweight, overweight, and obesity from 1975 to 2016: A pooled analysis of 2416 population-based measurement studies in 128. 9 million children, adolescents, and adults. Lancet. 2017;390(10113):2627-2642.

2. Di Angelantonio E, Bhupathiraju SN, Wormser D, Gao P, Kaptoge S, de Gonzalez AB, et al. Body-mass index and allcause mortality: Individual-participant-data meta-analysis of 239 prospective studies in four continents. Lancet. 2016;388(10046):776-786.
3. Pozza C, Isidori AM. What's behind the obesity epidemic. Imaging in bariatric surgery: Springer; 2018. p. 1-8. (https:// link.springer.com/chapter/10.1007/978-3-319-49299-5_1, Accessed Date:02.04.2019)

4. Ural D, Kılıçkap M, Göksülük H, Karaaslan D, Kayıkçığlu $\mathrm{M}$, Özer N, et al. Data on prevalence of obesity and waist circumference in Turkey: Systematic review, meta-analysis and meta regression of epidemiological studies on cardiovascular risk factors. Turk Kardiyol Dern Ars. 2018;46(7):577-590.

5. Organization WH. Obesity: preventing and managing the global epidemic: report of a WHO consultation on obesity, Geneva, 3-5 June 1997. Geneva: World Health Organization; 1998. (https://apps.who.int/iris/handle/10665/63854, Accessed Date:02.04.2019)

6. Report WHOJWT. Obesity: preventing and managing the global epidemic. 2000. 2000;894. (https://www.who.int/ nutrition/publications/obesity/WHO_TRS_894/en/, Accessed Date:02.04.2019)

7. Altan O, Şurdum G, Vc1 P, Şenocak M, Örnek E, Özcan R. Risk Faktörleri Sıklığı tarifi. (https://www.journalagent.com/ tkd/pdfs/TKDA_19_1_9_15.pdf, Accessed Date:02.04.2019)

8. Satman I, Yilmaz T, Sengül A, Salman S, Salman F, Uygur S, et al. Population-based study of diabetes and risk characteristics in Turkey: results of the turkish diabetes epidemiology study (TURDEP). Diabetes Care. 2002;25(9):1551-1556.

9. Satman I, Omer B, Tutuncu Y, Kalaca S, Gedik S, Dinccag N, et al. Twelve-year trends in the prevalence and risk factors of diabetes and prediabetes in Turkish adults. Eur J Epidemiol. 2013;28(2):169-180.

10. World Health Organization. WHO fact sheet on overweight and obesity. Updated October 2017. http://www.who. int/ mediacentre/factsheets/fs311/en/. Erişim tarihi: 8 Aralık2017.

11. Cesare MD, Bentham J, Stevens GA, Zhou B, Danaei G, Lu $\mathrm{Y}$, et al. Trends in adult body- mass index in 200 countries from 1975 to 2014: a pooled analysis of 1698 population-based measurement studies with 19.2 million participants. Lancet. 2016;387(10026):1377-1396.

12. Ginter E, Simko V. Type 2 diabetes mellitus, pandemic in 21st century. Diabetes: Springer; 2013. p.42-50. (https:// link.springer.com/chapter/10.1007/978-1-4614-5441-0_6, Accessed Date:02.04.2019)

13. Sofi F, Casini AJ, Wjog W. Mediterranean diet and nonalcoholic fatty liver disease: New therapeutic option around the corner? World J Gastroenterol. 2014;20(23):7339.

14. Keleş İ, Onat A, Sansoy V, Aksu H, Çetinkaya A, Yıldırım B, et al. TEKHARF 1997/98 Taramasi Yeni Kohortonda Risk Faktörleri ve Kalp Hastalıkları Prevalansı. Türk Kardiyol Dern Arş. 1999; 27: 104-109.

15. Organization WH. World report on disability 2011. (https://apps.who.int/iris/handle/10665/44575, Accessed Date:02.04.2019) 